\title{
TU/e EmonOWEN

\section{Measurement of low-frequency base and collector current noise and coherence in SiGe heterojunction bipolar transistors using transimpedance amplifiers}

\author{
Citation for published version (APA): \\ Bruce, S. P. O., Vandamme, L. K. J., \& Rydberg, A. (1999). Measurement of low-frequency base and collector \\ current noise and coherence in SiGe heterojunction bipolar transistors using transimpedance amplifiers. IEEE \\ Transactions on Electron Devices, 46(5), 993-1000. https://doi.org/10.1109/16.760408
}

DOI:

10.1109/16.760408

Document status and date:

Published: 01/01/1999

\section{Document Version:}

Publisher's PDF, also known as Version of Record (includes final page, issue and volume numbers)

\section{Please check the document version of this publication:}

- A submitted manuscript is the version of the article upon submission and before peer-review. There can be important differences between the submitted version and the official published version of record. People interested in the research are advised to contact the author for the final version of the publication, or visit the DOI to the publisher's website.

- The final author version and the galley proof are versions of the publication after peer review.

- The final published version features the final layout of the paper including the volume, issue and page numbers.

Link to publication

\footnotetext{
General rights

- You may freely distribute the URL identifying the publication in the public portal. follow below link for the End User Agreement:

www.tue.nl/taverne

\section{Take down policy}

If you believe that this document breaches copyright please contact us at:

openaccess@tue.nl

providing details and we will investigate your claim.
}

Copyright and moral rights for the publications made accessible in the public portal are retained by the authors and/or other copyright owners and it is a condition of accessing publications that users recognise and abide by the legal requirements associated with these rights.

- Users may download and print one copy of any publication from the public portal for the purpose of private study or research.

- You may not further distribute the material or use it for any profit-making activity or commercial gain

If the publication is distributed under the terms of Article 25fa of the Dutch Copyright Act, indicated by the "Taverne" license above, please 


\section{Measurement of Low-Frequency Base and Collector Current Noise and Coherence in SiGe Heterojunction Bipolar Transistors Using Transimpedance Amplifiers}

Staffan P. O. Bruce, Student Member, IEEE, L. K. J. Vandamme, Member, IEEE, and Anders Rydberg, Member, IEEE

\begin{abstract}
Transimpedance amplifiers have been used for direct study of current noise in silicon germanium (SiGe) heterojunction bipolar transistors (HBT's) at different biasing conditions. This has facilitated a wider range of resistances in the measurement circuit around the transistor than is possible when using a voltage amplifier for the same kind of measurements. The ac current amplification factor $h_{\mathrm{fe}}$ and the sum of the base and emitter series resistances $\left(r_{b}+r_{e}\right)$ have been extracted from the noise. It has been established that the dominant noise source is situated in the base emitter junction at the emitter side and is not related to contact resistance noise. The simultaneous measurement of both the base-lead noise and the collector-lead noise and the calculation of the coherence between the signals has facilitated the pinpointing of the dominant noise source in the device and the extraction of $\left(r_{b}+r_{e}\right)$.
\end{abstract}

Index Terms - HBT, low-frequency noise, silicon germanium (SiGe), transimpedance amplifiers.

\section{INTRODUCTION}

$\mathbf{T}$ HE major source of phase noise in microwave oscillators is the transistor low-frequency noise which modulates the carrier [1]. Therefore low-frequency investigations on prototype microwave transistors are a first step in trying to optimize the phase noise of an oscillator. The general approach up to now for studying the $1 / f$ noise in bipolar transistors is to use voltage amplifiers to measure the voltage fluctuations over a resistor which forms part of the measurement setup. By dividing the fluctuations in the voltage drop by the resistance value, a corresponding current noise is calculated. A first successful attempt has been carried out [2], [3] to use low-noise voltage amplifiers in Si bipolar transistors. Their configuration limits however the range of source and load resistances that can be used within the measurement. The present work aims at studying the current noise in base and collector current and their coherence in silicon germanium ( $\mathrm{SiGe}$ ) heterojunction bipolar transistors (HBT's) in a direct way, making use of ultra

Manuscript received October 7, 1998; revised December 17, 1998. The review of this paper was arranged by Editor W. Weber. This work was supported in part by The Swedish Strategic Foundation (SSF) through the microelectronics consortium "HF Bipolar Technology."

S. Bruce and A. Rydberg are with Uppsala University, Uppsala, Sweden.

L. K. J. Vandamme is with the Eindhoven University of Technology, The Netherlands.

Publisher Item Identifier S 0018-9383(99)03514-5.

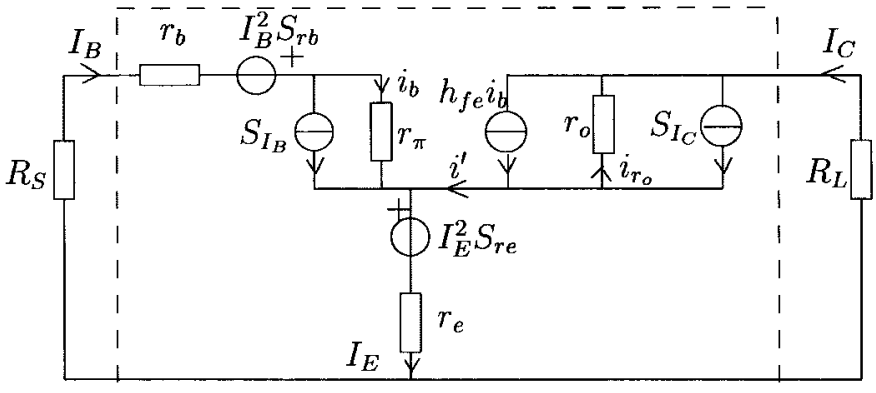

ᄂ $-\ldots-----------$ I

Fig. 1. Equivalent small signal circuit for an HBT in a common emitter measurement setup indicating the fundamental noise sources. The circuit inside the dotted rectangle corresponds to the transistor itself. $I_{B}$ and $I_{E}$ indicate steady state currents.

low-noise transimpedance amplifiers with or without internal biasing possibilities for measuring the current noise. These particular devices have been chosen for their pronounced noise in order to facilitate distinct measurements. Analysing the results shows where the dominant noise source is located. We will point out benefits and shortcomings with this technique.

\section{THEORY}

The noise sources of a bipolar transistor can schematically be presented as in Fig. 1 where the representation is made using resistance and current noise sources. $S_{r_{b}}, S_{r_{e}}, S_{I_{B}}$, and $S_{I_{C}}$ are the resistance fluctuations of the base and emitter resistances and the current fluctuation in the base-emitter junction and in the collector, respectively. The steady state currents are indicated by $I_{B}$ and $I_{E}$ and cause a voltage fluctuation as a result of $S_{r_{b}}$ and $S_{r_{e}} ; h_{\mathrm{fe}}$ is the ac current amplification factor; $r_{\pi}$ and $r_{0}$ are the dynamic input and output resistances of the transistor; $r_{b}$ and $r_{e}$ are the base and emitter resistances within the transistor and $R_{S}$ and $R_{L}$ are the source and load resistances within the measurement setup.

These sources can be further decomposed into different types of noise. $S_{I_{B}}$ and $S_{I_{C}}$ consist of shot noise, generationrecombination (GR) noise and $1 / f$ noise

$$
\begin{aligned}
& S_{I_{B}}=2 q I_{B}+S_{I_{B}}^{1 / f}+S_{I_{B}}^{G R} \\
& S_{I_{C}}=2 q I_{C}+S_{I_{C}}^{1 / f}+S_{I_{C}}^{G R} .
\end{aligned}
$$


Similarly, in general the sources due to conductance fluctuations $\left(S_{r_{b}}\right.$ and $\left.S_{r_{e}}\right)$ can be composed of GR noise, random telegraph signal (RTS) noise and $1 / f$ noise. The resistances $r_{b}$ and $r_{e}$ also contribute with Nyquist noise. The Nyquist noise can be seen as voltage sources in series with $I_{B}^{2} S_{r_{b}}$ and $I_{E}^{2} S_{r_{e}}$, but due to the heavy doping of both the base and the emitter, facilitated by the heterostructure, this noise is very low and has not been detected in measurements. They are thus not included in Fig. 1. Also the GR and RTS noise have not been observed and are therefore ignored in the discussion. From the equivalent circuit in Fig. 1 the theoretical expressions for the measured noise current spectra in the base $\left(S_{I_{B E}}\right)$ and the collector-lead $\left(S_{I_{C E}}\right)$ have been derived in the Appendix and are expressed as

$$
\begin{aligned}
S_{I_{B E}}= & \frac{1}{Z^{2}}\left[I_{B}^{2} S_{r_{b}}+r_{\pi}^{2} S_{I_{B}}+I_{E}^{2} S_{r_{e}}+r_{e}^{2} S_{I_{C}}\right] \\
S_{I_{C E}}= & \frac{h_{\mathrm{fe}}^{2}}{Z^{2}}\left[I_{B}^{2} S_{r_{b}}+Z_{S}^{\prime 2} S_{I_{B}}+I_{E}^{2} S_{r_{e}}\right. \\
& \left.+\frac{\left(R_{S}+r_{b}+r_{\pi}+r_{e}\right)^{2}}{h_{\mathrm{fe}}^{2}} S_{I_{C}}\right]
\end{aligned}
$$

The correlated spectrum between the two signals is expressed as

$$
\begin{aligned}
S_{I_{B E} I_{C E}}= & \frac{h_{\mathrm{fe}}}{Z^{2}}\left[I_{B}^{2} S_{r_{b}}-r_{\pi} Z_{S}^{\prime} S_{I_{B}}+I_{E}^{2} S_{r_{e}}\right. \\
& \left.-\frac{\left(R_{S}+r_{b}+r_{\pi}+r_{e}\right) r_{e}}{h_{\mathrm{fe}}} S_{I_{C}}\right]
\end{aligned}
$$

where

$$
\begin{aligned}
Z & =\left(R_{S}+r_{b}+r_{\pi}+\left(1+h_{\mathrm{fe}}\right) r_{e}\right) \\
Z_{S}^{\prime} & =\left(R_{S}+r_{b}+r_{e}\right)=Z-r_{\pi}-h_{\mathrm{fe}} r_{e} \\
I_{E} & =(1+\beta) I_{B} .
\end{aligned}
$$

Normally, in the active region, $\left(r_{o} /\left(R_{L}+r_{o}\right)\right) \approx 1$; and $\beta$ is the dc part of the current amplification factor. The minus sign in (5) is related to the different directions of the currents that this source generates in the two measurement leads. For the coherence defined as (the full expression can be found in the Appendix)

$$
\gamma^{2} \stackrel{\text { def }}{=} \frac{S_{I_{B E} I_{C E}}^{2}}{S_{I_{B E}} \cdot S_{I_{C E}}}
$$

holds $\gamma^{2}=1$ when a single noise source is dominant in both measurement leads, independent of $R_{S}$ and $R_{L}$.

In practice, the correlated spectrum $\left(S_{I_{B E} I_{C E}}\right)$ is calculated through a multiplication in the frequency domain between the complex Fourier transforms of the the two measured signals whose spectral power densities are $S_{I_{B E}}$ and $S_{I_{C E}}$. The coherence function is then calculated using its definition in (8).

\section{MEASUREMENT SETUP}

Using a measurement setup like the one in Fig. 2(a), current noise can be directly measured for a variety of lead resistances of the base $\left[R_{S}\right.$ in Fig. 1 and Fig. 2(a)]. Also the lead resistance of the collector can be varied, in order to find information
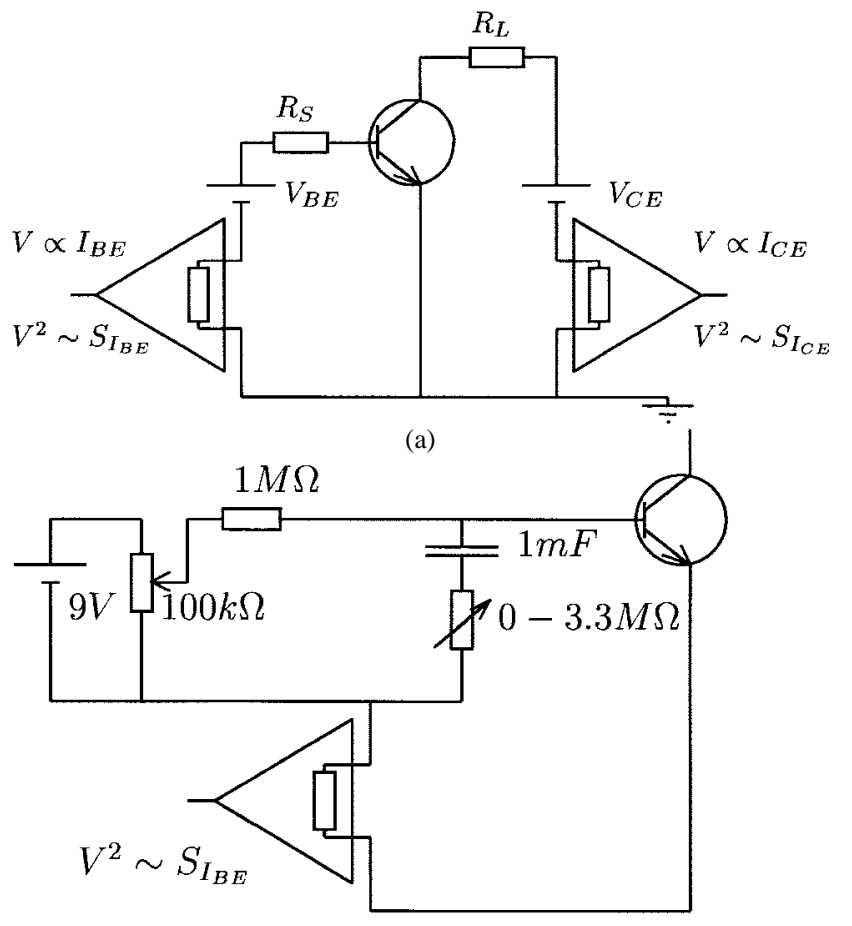

(b)

Fig. 2. Measurement setup. (a) The current passing through the transimpedance amplifiers are converted to an equivalent voltage which is measured using a double-channel low-frequency spectrum analyzer with the possibility to calculate the coherence between the two channels. (b) A close up of the biasing of the base current facilitating a precise control of the dc bias current and of the ac load impedance.

regarding the dynamic output resistance. In this investigation the external resistance in the collector lead has been held as low as possible which means that the nonnegligible internal resistance of the transimpedance amplifier in this lead has been dominating the resistance. This ensures that the whole noise current is measured. Due to the very low feedback from collector to base, the variation in impedance when changing range setting of the amplifier in the collector-lead does not affect the electrical behavior of the circuit and can thus be neglected.

Assuming the noise sources as shown in Fig. 1, the measured noise in the base-lead $\left(S_{I_{B E}}\right)$ and in the collector-lead $\left(S_{I_{C E}}\right)$ can be used for extracting information regarding the different noise sources within the device. Some advantages and drawbacks of transimpedance amplifiers will be discussed.

In order to keep control of the measurements, two different types of transimpedance amplifiers have been used for converting the measured current to a corresponding voltage: Brookdeal 5002 and Stanford Research Systems SR570. The latter facilitates internal voltage bias with a high resolution which can be controlled by a computer. This showed very useful when performing sweeps of the base current. However, caution must be taken not to nonintentionally induce noise in the system by using this internal voltage source. The Brookdeal 5002 does not have an internal biasing and induces very little noise into the measurement setup. An external voltage source with variable ac impedance [see Fig. 2(b)] has been realized, mainly based on a battery, a high-quality potentiometer and 
a variable resistance in series with a large capacitance. If the measuring of dc part of the current can be omitted, the transimpedance amplifier can be inserted in direct series with the capacitance and the variable resistance which can enable a higher amplification factor as the amplifier does not need to sink the dc current. A higher amplification factor results however also in a higher internal impedance within the amplifier which must be accounted for.

Measuring the noise currents directly with transimpedance amplifiers enables us to use a large range in source resistances. The only limitation is that the impedance of the measured circuit should be larger than the input impedance of the current amplifier. This is easily obtained with transistors where the dynamic resistance always is much higher than the input impedance of the amplifier for all current levels. This enables simultaneous measurements of both the base and collector current noise and calculation of their coherence directly. The measurements would be very difficult to perform using voltage amplifiers at low values of the source resistances since the signal would be drowned in the Nyquist noise of the resistor itself and the background noise of the amplifier. As an example, a measurement of the shot noise level, calculated as $2 q I$, using a $1 \mathrm{k} \Omega$ resistor and a voltage amplifier means the current $I$ must be higher than $50 \mu \mathrm{A}$ in order not to be drowned by the internal Nyquist noise of the resistor. This is a high current for small devices. Lower current noise levels would thus not be possible to detect without severely degrading the coherence calculation between the two measured signals due to uncorrelated noise contributions of the resistances $R_{L}$ and $R_{S}$.

By changing the sensitivity of the transimpedance amplifier, its internal impedance changes which appears as a variation in source impedance for the device under test. Attention to this behavior is given during measurements of current sweeps since both $S_{I_{B E}}$ and $S_{I_{B C}}$ can be affected by variation in impedance.

High current sensitivity goes hand in hand with a higher input impedance and a lower bandwidth. In addition to a limited bandwidth, the transimpedance amplifier exhibits an inductive behavior at the input which can introduce a resonance with a (parasitic) capacitance at the input. For this work, either a frequency of 20,25 , or $170 \mathrm{~Hz}$ has been chosen when comparing results of different bias conditions; mainly in order to avoid disturbance from harmonics of the $50 \mathrm{~Hz}$ power line signal, background noise and bandwidth problems. The reason for choosing the higher frequency of $170 \mathrm{~Hz}$ is due to the series capacitance for the ac impedance in the base lead [see Fig. 2(b)].

The internal bias supply of the SR570 amplifier enables a very compact solution for the measurement setup which makes it less prone to picking up undesired signals. However, owing to the very high open loop gain of the amplifier in the internal transimpedance stage, any fluctuation in the reference voltage for the bias will appear as an almost ideal voltage noise source at, e.g., the base of the transistor. This will affect both $S_{I_{B E}}$ and $S_{I_{C E}}$ and in worst case induce an undesired full coherence between the two measured noise signals. The same undesired noise source can also be unevenly partitioned between the two channels, especially for low values of $R_{S}$, where $S_{I_{C E}}$ is affected, which can result in a low coherence. Here the results of coherence between $S_{I_{B E}}$ and $S_{I_{C E}}$ without measurement artifacts will be presented by the usage of the Brookdeal 5002 where the SR570 is found insufficient after comparing the results with a Brookdeal 5002.

\section{RESULTS}

Measured current noise spectra of a $20-\mu \mathrm{m}^{2}$ device for the base-lead and collector-lead is shown in Fig. 3. The curves indicate a spectra with $1 / f^{0.8}$ dependence below $10 \mathrm{kHz}$ which is in accordance with results for similar devices [4]. The level of the noise is too high for any white noise to be seen within the measured frequency range. Furthermore, the noise measurements at low currents are limited by the bandwidth of the amplifier which can be seen as a distinct roll-off above $10 \mathrm{kHz}$. A plot of coherence between the two noise spectra measured at any given base current shows a value very close to unity, see Fig. 3. This indicates that the measured noise originates from a common source, thus excluding any dominant source in the collector-lead and hence $S_{I_{B}}, S_{r_{b}}$, or $S_{r_{e}}$ are the possible candidates.

In order to discriminate, we measure the current spectra at approximately constant values of base and collector current for a range of source resistances $\left(R_{S}\right.$ in Fig. 2). We deduce from (4) and (7) and our experimental results that $S_{I_{B}}$ is the single dominant source for almost all values of $R_{S}$. A more thorough explanation will follow.

As can be seen in Fig. 4, $S_{I_{C E}}$ shows a square dependence on $R_{S}$ for values of $300 \Omega \leq R_{S} \leq r_{\pi}$ which indicates strongly that $S_{I_{B}}$ can be the only source, as can be seen from the second term in (4). All other components in (4) are for these values of $R_{S}$ either independent of, or only very weakly dependent on $R_{S}$. In this region of $R_{S}$, the coherence $(\gamma)$ is very close to unity, thus indicating that the same source is totally dominant also in $S_{I_{B E}}$. This means however that $S_{I_{B}}$ is dominant in $S_{I_{B E}}$ for all values of $R_{S}$ since the interdependence between the different terms in $S_{I_{B E}}$ is independent of $R_{S}$, [see (3)].

For low values of $R_{S}$, the coherence goes down (see Fig. 4) which indicates that at least one additional source (here called $S_{X}$ ) becomes significant in $S_{I_{C E}}$. The origin of this source is difficult to distinguish as the measured noise levels at these values of $R_{S}$ are very low and thus external noise may enter, but from (5) or (36), shown at the bottom of the page, it can be indicated that $S_{I_{C}}$ is a candidate since $\gamma^{2}$ never drops to zero. To pinpoint the source, a more thorough investigation would however be necessary which is beyond the scope of this paper. Assuming that this source is independent of $R_{S}$ and bearing in mind that $S_{I_{B E}}$ is completely dominated by $S_{I_{B}}, S_{X}$ is calculated as

$$
S_{X}=\left(1-\gamma^{2}\right) S_{I_{C E}} .
$$

The coherence does however not reach zero for the given range of $R_{S}$ thus indicating that $S_{I_{B}}$ still contributes to $S_{I_{C E}}$. This level is calculated (here called $S_{I_{C E_{1}}}$ ) as

$$
S_{I_{C E_{1}}}=\gamma^{2} S_{I_{C E}}
$$




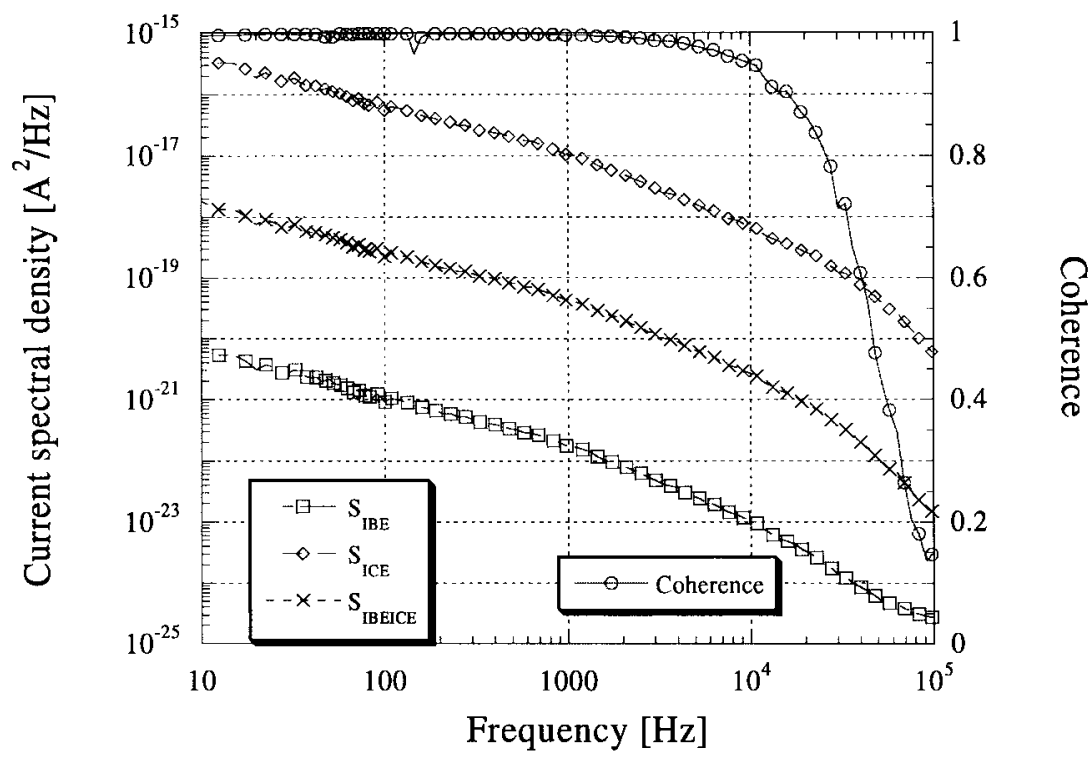

Fig. 3. Measured current noise spectrum through the base and collector-lead for a $20 \mu \mathrm{m}^{2}$ device. Coherence between the two signals is included. The source resistance is set to $R_{S}=10 \mathrm{k} \Omega$ and $I_{B}$ was set to $1 \mu \mathrm{A}$. The roll-off at higher frequencies for the curves is due to the limited bandwidth of the transimpedance amplifiers.

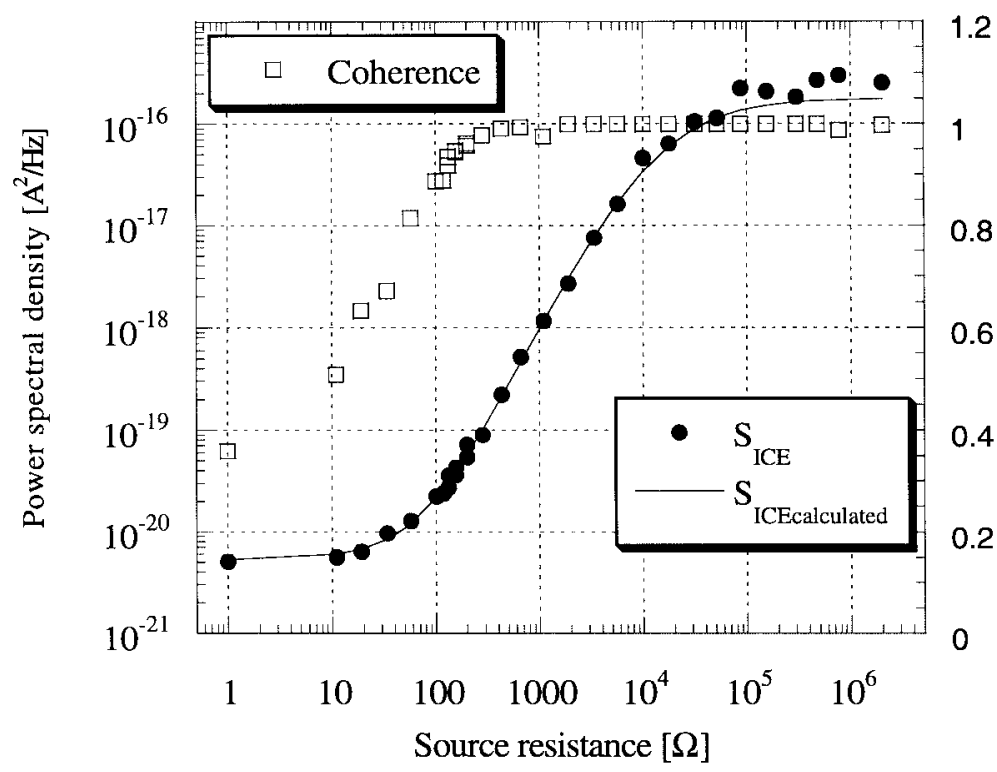

Fig. 4. Measured and calculated data of $S_{I_{C E}}$ versus $R_{S}$ for a $24 \mu \mathrm{m}^{2}$ device at $V_{C E}=1.5 \mathrm{~V}, I_{B}=2 \mu \mathrm{A}$ and $f=170 \mathrm{~Hz}$. Calculated data

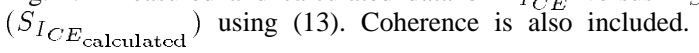

and the value of $\left(R_{S}+r_{b}+r_{e}\right)$ can be extracted as a factor in front of $S_{I_{B}}$, see (3). Note that in this region, $R_{S} \ll r_{\pi}$.

For the extraction, a measurement (here called $S_{I_{C E_{2}}}$ ) of $S_{I_{C E}}$ is taken where $S_{I_{B}}$ is dominant and $R_{S} \gg\left(r_{b}+r_{e}\right)$. The quotient between $S_{I_{C E_{1}}}$ and $S_{I_{C E_{2}}}$ will then be (neglecting insignificant terms)

$$
\frac{S_{I_{C E_{1}}}}{S_{I_{C E_{2}}}}=\left(\frac{\left(R_{S_{1}}+r_{b}+r_{e}\right)\left(R_{S_{2}}+r_{\pi}\right)}{R_{S_{2}} r_{\pi}}\right)^{2}
$$

and $\left(r_{b}+r_{e}\right)$ is found as

$$
\left(r_{b}+r_{e}\right)=\sqrt{\frac{S_{I_{C E_{1}}}}{S_{I_{C E_{2}}}}}\left(\frac{R_{S_{2}} r_{\pi}}{R_{S_{2}}+r_{\pi}}\right)-R_{S_{1}}
$$

where $R_{S_{1}}$ and $R_{S_{2}}$ are the values of $R_{S}$ for the measurements of $S_{I_{C E_{1}}}$ and $S_{I_{C E_{2}}}$, respectively. An average of the extracted values for $R_{S_{1}}=1,11,19$, and $34 \Omega$ (indicating values of $S_{I_{C E}}$ where the coherence clearly differs from unity) and $R_{S_{2}}=3.4 \mathrm{k} \Omega$ gives $S_{X}=4.4 \cdot 10^{-21} \mathrm{~A}^{2} / \mathrm{Hz}$ at $f=170 \mathrm{~Hz}$ and $\left(r_{b}+r_{e}\right)=28 \Omega$.

Under the assumption that only the sources $S_{I_{B}}$ and $S_{X}$ contribute to $S_{I_{C E}}$, a simplified expression is found as

$$
S_{I_{C E_{\text {calculatcd }}}}=S_{I_{C E_{0}}}\left(\frac{Z^{\prime}}{Z}\right)^{2}+S_{X} .
$$

Thus, only one additional parameter, here called $S_{I_{C E_{0}}}$, needs to be extracted to be able to calculate $S_{I_{C E}}$. From (4) it 


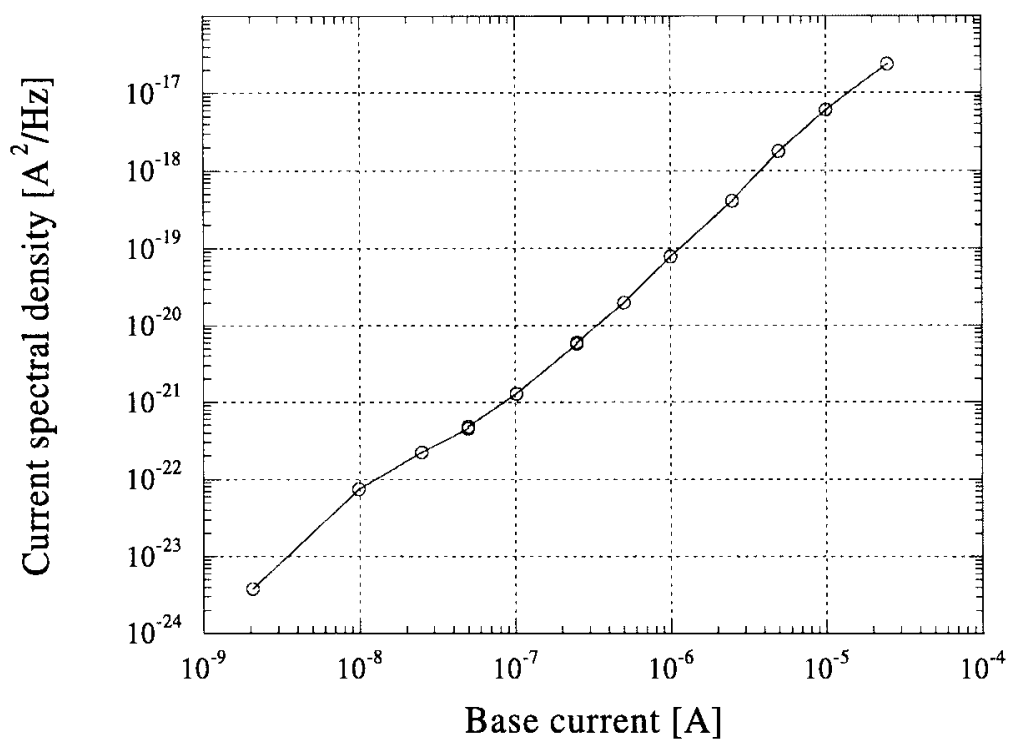

Fig. 5. Extracted values of $S_{I_{B}}$ versus $I_{B}$ on a $20 \mu \mathrm{m}^{2}$ device. Measurements done at $f=25 \mathrm{~Hz}, V_{C E}=1.5 \mathrm{~V}$ and $R_{S}=100 \mathrm{k} \Omega$.

is found that this corresponds to $h_{\mathrm{fe}}{ }^{2} S_{I_{B}}$. However, in order to gain as much information as possible from the measured $S_{I_{C E}}$ and not include uncertainty from additional circuit parameters, a calculation of this term is omitted in favor of a direct extraction. In a region where $\left(r_{b}+r_{e}\right) \ll R_{S}<r_{\pi} / 2, S_{I_{B}}$ is dominant, $S_{I_{C E_{0}}}$ is found as

$$
S_{I_{C E_{0}}}=S_{I_{C E}}\left(\frac{R_{S}+r_{\pi}}{R_{S}+\left(r_{b}+r_{e}\right)}\right)^{2}
$$

For $500 \Omega \leq R_{S} \leq 6 \mathrm{k} \Omega$ and $f=170 \mathrm{~Hz}$ an average of $S_{I_{C E_{0}}}$ was found to be $1.8 \cdot 10^{-16} \mathrm{~A}^{2} / \mathrm{Hz}$. This compares very well with the calculated value found using extracted $h_{\mathrm{fe}}$ and $S_{I_{B}}$.

The curve of $S_{I_{C E_{\text {calculated }}}}$ has been included in Fig. 4 as a full line and compares very well with measured data (dots), thus showing that the assumptions are correct. From the shape of $S_{I_{C E}}$, it can be seen that there is a lower limit to which there is any point in setting the biasing impedance, $R_{S}$, and this is above the value of $\left(r_{b}+r_{e}\right)$. Furthermore, as biasing impedance increases, $S_{I_{C E}}$ rolls off, indicating that bias impedances chosen above the value of $r_{\pi}$ does not further increase $S_{I_{C E}}$. An implication of this is that devices with a high $\beta$ will have a high range of $S_{I_{C E}}$ depending on which biasing impedance is chosen since $I_{B}$ here is small and thus $r_{\pi}$ becomes large, giving a large span of values between $\left(r_{b}+r_{e}\right)$ and $r_{\pi}$.

Using (4) and (5), a value for $h_{\mathrm{fe}}$ is found as

$$
h_{\mathrm{fe}}=\frac{S_{I_{C E}}}{S_{I_{B C} I_{C E}}} \frac{r_{\pi}}{R_{S}}
$$

assuming $R_{S} \gg\left(1+h_{\mathrm{fe}}\right) r_{e}, S_{I_{B}}$ is the dominant noise source and $\left(r_{o} /\left(R_{L}+r_{o}\right)\right) \rightarrow 1$. Extracted values using (15) and data from the Gummel plot are compared in Table I.

A value of $S_{I_{B}}$ is calculated as

$$
S_{I_{B}}=S_{I_{B E}} * \frac{\left(R_{S}+r_{\pi}\right)^{2}}{r_{\pi}^{2}}
$$

TABLE I

Extracted Values of $h_{\mathrm{fe}}$ For a $20 \mu \mathrm{m}^{2}$ Device At Different Values of $I_{B}$ Using (15). $f=25 \mathrm{~Hz}, R_{S} 100 \mathrm{k} \Omega$ AND $V_{C E}=1.5 \mathrm{~V}$. THE Column $\delta I_{C} / \delta I_{B}$ Indicates Extracted Data From a Gummel Plot

\begin{tabular}{rl|r|r}
\hline$I_{B}$ & & $h_{f e}$ & $\frac{\delta I_{C}}{\delta I_{B}}$ \\
\hline 20 & $\mathrm{nA}$ & 35 & 38 \\
200 & $\mathrm{nA}$ & 48 & 58 \\
1 & $\mu \mathrm{A}$ & 64 & 79 \\
2.6 & $\mu \mathrm{A}$ & 110 & 108 \\
10 & $\mu \mathrm{A}$ & 120 & 177 \\
\hline
\end{tabular}

for values of $R_{S} \gg r_{b}+\left(1+h_{\mathrm{fe}}\right) r_{e}$. In particular, for $\left(r_{b}+\left(1+h_{\mathrm{fe}}\right) r_{e}\right) \ll R_{S} \ll r_{\pi}$ we have $S_{I_{B}} \approx S_{I_{B E}}$.

A dependence on base current of approximately $I_{B}^{1.7}$ has been measured throughout the available bias range, see Fig. 5 . For currents below $250 \mathrm{nA}$, the frequency dependence if the noise is weaker and bandwidth limitations play a role. The reduced frequency dependence of $S_{I_{B}}$ in conjunction with the current dependence indicate that the noise source is not of pure $1 / f$-type and any real predictions on corner frequencies where the low-frequency noise disappears in the shot noise are difficult to make [5].

The current dependence of $S_{I_{B}}$ gives space for interpretations of the origin of the noise. As shown earlier, the noise originates within the base-emitter junction which here means not in the base resistance and not in the emitter resistance. Assuming a true area dependent effect, the mobility fluctuation model or the number fluctuation model seem to be reasonable candidates. The Kleinpenning model considers mobility fluctuations and hence fluctuations in the diffusion coefficient for the minority carriers. A simplified relation, which indicates a linear dependence of $S_{I_{B}}$ on current, is given as follows [6]:

$$
S_{I_{B}}=\frac{2 \alpha q I_{B} D_{p}}{f W_{E}^{2}}
$$

where $D_{p}$ is the hole diffusion coefficient in the emitter of an NPN transistor and $W_{E}$ is the length of the undepleted part of the emitter. With $D_{p}=5 \mathrm{~cm}^{2} / \mathrm{s}, W_{E}=1.2 * 10^{-5} \mathrm{~cm}$ and 
$f=25 \mathrm{~Hz}$, calculated $\alpha$ for $I_{B}=250 \mathrm{nA}$ and $I_{B}=25 \mu \mathrm{A}$ give values of $5 * 10^{-5}$ and $2 * 10^{-3}$, respectively, which is within reasonable limits [7]. Due to the variation in base current, the depletion region in the emitter vary and thus also the region where the fluctuation in mobility will be of greatest importance. The fact that $\alpha$ is nonuniform can speak for a position dependence on $\alpha$ in the $W_{E}$ region just at the rim of the depletion region [8].

The number fluctuation model considers a fluctuation in the surface recombination velocity, $s$. With the relation for short diodes [9]

$$
\frac{S_{I}}{I^{2}}=C \cdot S_{s}
$$

where $C$ is independent of current and $S_{s}$ is the spectral density of the fluctuations in $s$ with a $1 / f$-type of spectrum. It can be seen that this model predicts a square-law dependence on current just like series resistance fluctuations. This model thus fits to the "near-square-law" dependence of $S_{I_{B}}$ which has been observed.

\section{CONCLUSION}

We have used transimpedance amplifiers for direct study of current noise in a silicon germanium HBT at different biasing conditions. The possibility of measuring the device using a wider range of external resistances than is possible when using a voltage amplifier has facilitated extraction of the ac current amplification factor $h_{\mathrm{fe}}$ and the sum of the base and emitter series resistances $\left(r_{b}+r_{e}\right)$. The simultaneous measurement of both the base-lead noise and the collector-lead noise has enabled a calculation of the coherence between the signals. From the high coherence and the dependence of collector-lead noise on source resistance, it has been established that the dominant noise source is situated in the base emitter junction, in the $W_{E}$ region at the emitter side and not in the contact resistances $r_{b}$ and $r_{e}$. The use of the coherence function has been essential for the discrimination of the dominant noise source and for the extraction of $\left(r_{b}+r_{e}\right)$.

\section{APPENDIX \\ DERIVATION OF $S_{I_{C E}}, S_{I_{B E}}, S_{I_{B E} I_{C E}}$, AND $\gamma^{2}$ AND} ESTIMATION OF THE IMPACT OF $S_{I_{C}}$ ON THE MEASUREMENTS

This Appendix gives a more thorough description of how the important expressions for $S_{I_{C E}}, S_{I_{B E}}, S_{I_{B E} I_{C E}}$, and $\gamma^{2}[(3)-(5)$ and (8)] are derived. The expressions will be derived in steps, concentrating on one source at a time and finally collecting the the different parts to the full expressions.
A. Derivation of $S_{I_{C E}}, S_{I_{B E}}$, and $S_{I_{B E} I_{C E}}$ with Respect to $S_{I_{C}}$

The emphasis is first put on finding the impact of a noise source in the collector lead on the noise in the base lead. From Fig. 1, we define the following currents when $S_{I_{C}}$ is the only contributor:

$$
\left\{\begin{array}{l}
i^{\prime}=i_{S_{I_{C}}}-i_{r_{o}}+h_{\mathrm{fe}} i_{b} \\
i_{b}=-i^{\prime} \frac{r_{e}}{R_{S}+r_{b}+r_{\pi}+r_{e}} \\
i_{r_{o}}=i^{\prime} \frac{R_{L}+\left(R_{S}+r_{b}+r_{\pi}\right) \| r_{e}}{r_{o}} .
\end{array}\right.
$$

Elimination then gives (20) and (21), shown at the bottom of the page, where

$$
\left(R_{S}+r_{b}+r_{\pi}\right) \| r_{e} \stackrel{\text { def }}{=} \frac{\left(R_{S}+r_{b}+r_{\pi}\right) * r_{e}}{\left(R_{S}+r_{b}+r_{\pi}\right)+r_{e}} .
$$

For a common emitter configuration, $r_{o}, r_{\pi} \gg r_{e}$ and $R_{L}$ can be chosen very small and it is thus possible to assume that $r_{o}, r_{\pi} \gg\left(r_{e}+R_{L}\right)$, thus

$$
\begin{aligned}
& i_{b}=-i_{S_{I_{C}}} \frac{r_{e}}{Z} \\
& i^{\prime}=i_{S_{I_{C}}} \frac{R_{S}+r_{b}+r_{\pi}+r_{e}}{Z}
\end{aligned}
$$

where

$$
Z=\left(R_{S}+r_{b}+r_{\pi}+\left(1+h_{\mathrm{fe}}\right) r_{e}\right)
$$

It can be seen in Fig. 1 that $i^{\prime}$ is the same as the current flowing through $R_{L}$. Straightforward circuit analysis thus gives

$$
\begin{aligned}
S_{I_{B E}} & =\frac{r_{e}{ }^{2} S_{I_{C}}}{Z^{2}} \\
S_{I_{C E}} & =\frac{h_{\mathrm{fe}}^{2}}{Z^{2}} \frac{\left(R_{S}+r_{b}+r_{\pi}+r_{e}\right)^{2}}{h_{\mathrm{fe}}^{2}} S_{I_{C}} .
\end{aligned}
$$

Again it has been assumed that $r_{o} \gg\left(r_{e}+R_{L}\right)$.

The correlated spectrum between the two signals is expressed as [in the text (5)]

$$
S_{I_{B E} I_{C E}}=\frac{h_{\mathrm{fe}}}{Z^{2}} \frac{\left(R_{S}+r_{b}+r_{\pi}+r_{e}\right) r_{e}}{h_{\mathrm{fe}}} S_{I_{C}} .
$$

Can the source in the collector lead (i.e., $S_{I_{C}}$ ) be dominant?

If this is the case, we should find for the quotient between the power spectral densities of the measured signals

$$
\frac{S_{I_{C E}}}{S_{I_{B E}}}=\left(\frac{R_{S}+r_{b}+r_{\pi}+r_{e}}{r_{e}}\right)^{2} .
$$

$$
\begin{aligned}
& i_{b}=-i_{S_{I}}\left[\frac{r_{e}}{R_{S}+r_{b}+r_{\pi}+r_{e}}\right]\left\{\frac{1}{1+\frac{R_{L}+\left(R_{S}+r_{b}+r_{\pi}\right) \| r_{e}}{r_{o}}+h_{\mathrm{fe}} \frac{r_{e}}{R_{S}+r_{b}+r_{\pi}+r_{e}}}\right\} \\
& i^{\prime}=i_{S_{I_{C}}} \frac{1}{1+\frac{R_{L}+\left(R_{S}+r_{b}+r_{\pi}\right) \| r_{e}}{r_{o}}+h_{\mathrm{fe}} \frac{r_{e}}{R_{S}+r_{b}+r_{\pi}+r_{e}}}
\end{aligned}
$$




$$
\gamma^{2}=\frac{\left[I_{B}^{2} S_{r_{b}}-r_{\pi} Z_{S}^{\prime} S_{I_{B}}+I_{E}^{2} S_{r_{e}}-\frac{\left(R_{S}+r_{b}+r_{\pi}+r_{e}\right) r_{e}}{h_{\mathrm{fe}}} S_{I_{C}}\right]^{2}}{\left[I_{B}^{2} S_{r_{b}}+\left(r_{\pi}+h_{\mathrm{fe}} r_{e}\right)^{2} S_{I_{B}}+I_{E}^{2} S_{r_{e}}+r_{e}^{2} S_{I_{C}}\right]\left[I_{B}^{2} S_{r_{b}}+Z_{S}^{\prime 2} S_{I_{B}}+I_{E}^{2} S_{r_{e}}+\frac{\left(R_{S}+r_{b}+r_{\pi}+r_{e}\right)^{2}}{h_{\mathrm{fe}}^{2}} S_{I_{C}}\right]}
$$

For a base current $I_{B}=1 \mu \mathrm{A}, \quad r_{\pi} \approx 25 \mathrm{k} \Omega$. Assuming $r_{e}<10 \Omega$ which is well above the value found from $\mathrm{dc}$ analysis and neglecting $R_{S}$ in order to get a worst case value, this gives from (25)

$$
\frac{S_{I_{C E}}}{S_{I_{B E}}}>6 \cdot 10^{6}
$$

However, at $I_{B}=1 \mu \mathrm{A}$ (see Fig. 3) the ratio between $S_{I_{C E}}$ and $S_{I_{B E}}$ is less than $5 \cdot 10^{4}$ and $S_{I_{C}}$ can thus not be the dominant noise source.

B. Derivation of $S_{I_{C E}}, S_{I_{B E}}$, and $S_{I_{B E} I_{C E}}$ with Respect to $S_{r_{b}}, S_{r_{e}}$ and $S_{I_{B}}$, Ignoring $S_{I_{C}}$

Call current flowing through $R_{S}$ from basenode to ground as $i_{\mathrm{be}}$. Assume that the value of $r_{o}$ is high which means it does not shunt any significant current in comparison with $h_{\mathrm{fe}} i_{b}$.

To begin with, we study the different components in $S_{I_{B E}}$. Looking first at the impact of $S_{r_{b}}$, i.e., this being the only source. Call voltage caused by $I_{B}{ }^{2} S_{r_{b}}$ as $u_{S_{r_{b}}}$. Kirchoffs law gives

$$
u_{S_{r_{b}}}-i_{b} r_{\pi}-\left(i_{b}+h_{\mathrm{fe}} i_{b}\right) r_{e}+i_{\mathrm{be}} R_{S}-i_{b} r_{b}=0 .
$$

Notice that $i_{\mathrm{be}}=-i_{b}$. This gives immediately

$$
S_{I_{B E}}=\frac{I_{B}^{2} S_{r_{b}}}{Z^{2}}
$$

Second, looking at the impact of $S_{r_{e}}$, i.e., this being the only source. Call voltage caused by $I_{E}^{2} S_{r_{e}}$ as $u_{S_{r_{e}}}$. Kirchoff's law gives

$$
u_{S_{r e}}-\left(i_{b}+h_{\mathrm{fe}} i_{b}\right) r_{e}+i_{\mathrm{be}} R_{S}-i_{b} r_{b}-i_{b} r_{\pi}=0 .
$$

Notice that $i_{\mathrm{be}}=-i_{b}$. This gives immediately

$$
S_{I_{B E}}=\frac{I_{E}^{2} S_{r_{e}}}{Z^{2}} .
$$

Third, looking at the impact of $S_{I_{B}}$, i.e., this being the only source. Call current caused by $S_{I_{B}}$ as $i_{S_{I_{B}}}$. Notice that

$$
-i_{\mathrm{be}}-i_{S_{I_{B}}}-i_{b}=0 .
$$

Kirchoff's law gives

$$
i_{\mathrm{be}} R_{S}+i_{\mathrm{be}} r_{b}-i_{b} r_{\pi}-\left(i_{S_{I_{B}}}+i_{b}+h_{\mathrm{fe}} i_{b}\right) r_{e}=0 .
$$

Substitution of $i_{b}$ using (30) gives

$$
\begin{gathered}
i_{\mathrm{be}}\left(r_{b}+R_{S}+r_{\pi}+\left(1+h_{\mathrm{fe}}\right) r_{e}\right) \\
+i_{S_{I_{B}}}\left(r_{\pi}+h_{\mathrm{fe}} r_{e}\right)=0
\end{gathered}
$$

which yields

$$
S_{I_{B E}}=S_{I_{B}} \frac{\left(r_{\pi}+h_{\mathrm{fe}} r_{e}\right)^{2}}{Z^{2}}
$$

and in total for all sources

$$
S_{I_{B E}}=\frac{1}{Z^{2}}\left[I_{B}^{2} S_{r_{b}}+\left(r_{\pi}+h_{\mathrm{fe}} r_{e}\right)^{2} S_{I_{B}}+I_{E}^{2} S_{r_{e}}+r_{e}{ }^{2} S_{I_{C}}\right] .
$$

Continuing with $S_{I_{C E}}$, using the already found expressions [(26) and (28)], the impact on $S_{I_{C E}}$ from $S_{r_{b}}$ and $S_{r_{e}}$ can be found by noticing that in these cases $-i_{\mathrm{be}}=i_{b}$ and the current through $R_{L}$ is $i_{b} h_{\mathrm{fe}}$ The impact of $S_{I_{B}}$ on $S_{I_{C E}}$ can be found by using (30) and (32)

$$
i_{b}=-i_{S_{I_{B}}}\left[\frac{R_{S}+r_{b}+r_{e}}{Z}\right] .
$$

Thus, $S_{I_{C E}}$ will be

$$
\begin{aligned}
S_{I_{C E}}= & \frac{h_{\mathrm{fe}}^{2}}{Z^{2}}\left[I_{B}^{2} S_{r_{b}}+Z_{S}^{\prime 2} S_{I_{B}}+I_{E}^{2} S_{r_{e}}\right. \\
& \left.+\frac{\left(R_{S}+r_{b}+r_{\pi}+r_{e}\right)^{2}}{h_{\mathrm{fe}}^{2}} S_{I_{C}}\right]
\end{aligned}
$$

where

$$
Z_{S}^{\prime}=\left(R_{S}+r_{b}+r_{e}\right)
$$

and $S_{I_{B E} I_{C E}}$ can be found as (noticing the direction of the different current components)

$$
\begin{aligned}
S_{I_{B E} I_{C E}}= & \frac{h_{\mathrm{fe}}}{Z^{2}}\left[I_{B}^{2} S_{r_{b}}-r_{\pi} Z_{S}^{\prime} S_{I_{B}}+I_{E}^{2} S_{r_{e}}\right. \\
& \left.-\frac{\left(R_{S}+r_{b}+r_{\pi}+r_{e}\right) r_{e}}{h_{\mathrm{fe}}} S_{I_{C}}\right] .
\end{aligned}
$$

\section{The Full Expression of $\gamma^{2}$}

Given the expressions for $S_{I_{B E}}, S_{I_{C E}}$, and $S_{I_{B E} I_{C E}}$, the expression for $\gamma^{2}$ can be calculated from its definition (8) and is found to be (36), shown at the top of the page.

\section{ACKNOWLEDGMENT}

The authors wish to thank an anonymous reviewer for comments improving the final manuscript. The authors are thankful to J. Briaire, Eindhoven University of Technology, The Netherlands, for providing a LabView program controlling the double-channel Advantest R9211E FFT spectrum analyzer. The work was done at Eindhoven University of Technology, The Netherlands. 


\section{REFERENCES}

[1] O. Llopis, J. Verdier, M. Regis, R. Plana, M. Gayral, and J. Graffeuil, "Correlation between microwave transistors low-frequency noise, amplifiers residual phase noise and oscillators phase noise," in Microwave Physics and Technique, Proceedings of the NATO Advanced Research Workshop. Dordrecht, Netherlands: Kluwer, 1997, pp. 19-33.

[2] S. Jarrix, C. Delseny, F. Pascal, and G. Lecoy, "Noise correlation measurements in bipolar transistors. I. Theoretical expressions and extracted current spectral densities," J. Appl. Phys., vol. 81, pp. 2651-2657, Mar. 1997.

[3] C. Delseny, F. Pascal, S. Jarrix, and G. Lecoy, "Noise correlation measurements in bipolar transistors. II. Correlation between base and collector currents," J. Appl. Phys., vol. 81, pp. 2658-2665, Mar. 1997.

[4] L. Vempati, J. D. Cressler, J. A. Babcock, R. C. JAeger, and D. L. Harame, "Low-frequency noise in UHV/CVD epitaxial Si and SiGe bipolar transistors," IEEE J. Solid-State Circuits, vol. 31, pp. 1458-1467, Oct. 1996.

[5] A. Gruhle and C. Mähner, "Low 1/ $f$ noise SiGe HBT's with application to low phase noise microwave oscillators," Electron. Lett., vol. 33, pp. 2050-2052, Nov. 1997

[6] T. G. M. Kleinpenning, "Location of low-frequency noise in submicron bipolar transistors," IEEE Trans. Electron Devices, vol. 39, pp. 1501-1506, 1992

[7] L. K. J. Vandamme, "Is the $1 / f$ noise parameter $\alpha$ a constant?," in Proc. 7th Int. Noise Conf., Noise in Physical Systems and $1 / f$ Noise, 1983, pp. 183-192.

[8] L. K. J. Vandamme, E. P. Vandamme, and J. J. Dobbelsteen, "Impact of silicon substrate, iron contamination and perimiter on saturation current and noise in $\mathrm{n}^{+} \mathrm{p}$ diodes," Solid State Electron., vol. 41, pp. 901-908, 1997.

[9] T. G. M. Kleinpenning, " $1 / f$ noise in p-n junction diodes," J. Vac. Sci. Technol. A, vol. 3, pp. 178-182, Jan./Feb. 1985.

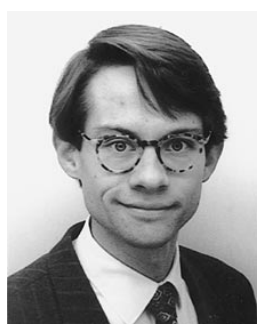

Staffan P. O. Bruce (S'94) was born in Göteborg, Sweden, in 1968. He received the M.Sc. degree in applied physics and electrical engineering from Linköping University, Sweden, in 1994. He is currently pursuing the Ph.D. degree at Uppsala University, Uppsala, Sweden.

His main interests concern modeling of highfrequency Si/SiGe HBT's, high-frequency applications, and $1 / f$-noise in semiconductors.



L. K. J. Vandamme (M'99) was born in Panne, Belgium, in 1943. He received the B.S. degree from H. T. I. Oostende, Belgium, in 1965, the M.S. degree in electrical engineering (cum laude) from the Delft University of Technology, The Netherlands, in 1971, and the doctorate degree from Eindhoven University of Technology, The Netherlands, in 1976.

Currently, he is with the Eindhoven University of Technology, the Netherlands. He has done research on $1 / f$ noise in electrical contacts, and thin- and thick-film resistors and optoelectronic devices. His current areas of research interest are $1 / f$ noise in submicron MOSFET's, bipolar transistors and conductive adhesives. He has authored or coauthored more than 120 publications. During 1981-1982, 1987, 1992, and 1998, he was a Visiting Professor at the University of Science and Technology, Montpellier, France.



Anders Rydberg (M'89) was born in Lund, Sweden, in 1952. He received the M.Sc. degree from Lund Institute of Technology, Lund, in 1976, and the degree of Licentiate of Engineering and the Ph.D. degree from Chalmers University of Technology, Sweden, in 1986 and 1988, respectively.

He worked between 1977 and 1983 with the development and research at the National Defense Research Establishment, ELLEMTEL Development Company, and the Onsala Space Observatory. From 1990 to 1991, he was a Senior Research Engineer at Farran Technology Ltd. Ireland. In 1991, he was appointed Docent (Associated Professor) in Applied Electron Physics at Chalmers University of Technology. In 1992, he became Associated Professor at the Signal and Systems Group at Uppsala University School of Technology. Since 1996, he has also Associated Professor and Research Leader part-time at the University College Gävle-Sandviken. His main interests are micro- and millimeter-wave solid state components and circuits for radio communication. He has authored or coauthored more than 70 papers in the above research area. He is also a co-owner of one patent on applications of single-barrier-varactor diodes.

Dr. Rydberg is a member of the editorial board for IEEE TRANSACTIONS on Microwave Theory and Techniques and delegate in the Swedish URSI-Sections B and D. 